\title{
Effects of Water Spray Timing After Pollination on Fruit Set, Yield, Physical and Chemical Properties of Two Date Palm Cultivars
}

\author{
Alasasfa, Muawya \\ Plant production Department, Faculty of Agriculture, Mu'tah University, Mu'tah, Karak, Jordan
}

\begin{abstract}
Field experiment was carried out at Ghour AlSafi in Jordan valley to study the effect of water spray time on Fruit set, yield and some characteristics on two date palm Cultivar ( Hayani and Zaghloly). Results of this investigation have showed that control treatment ( without water spray) has better fruit set and yield in both cultivar, but has less fruit weight owing to the increase of yield. The least fruit set was noticed when water had been sprayed after 3 hours from pollination. The water timing spray did not significantly affected fruit length, diameter, flesh and seed weight, total and reducing sugars in Zaghloly date. On the other hand, Hayani dates was significantly affected by water timing spray particularly fruit diameter, length / diameter ratio and TSS.
\end{abstract}

Keywords: Hababuk; Kimri; Hayani; Zaghloly; Hand pollination; Pollen grain germination.

DOI: $10.7176 / \mathrm{JBAH} / 9-10-08$

Publication date:May $31^{\text {st }} 2019$

\section{Introduction}

Date palm trees classified as a dioecious plant. The pollination could be defined as transfer of pollen grain from male to female tree either by hand or mechanical .In the absence of pollination, female flowers are not fertilized, and this leads to the development of three carpels to three small fruits, and consequently will drop after that.

Pollination can adversely be affected by, temperature; humidity, pollen grain viability, and ability of female flowers to receipt pollen grain (Hussein, 1987). Khalifa et al, (1983), stated that, the big difference in fruit set from one year to another is mainly due to climatic conditions.

Date palm is considered a desert tree, so that rain could cause negative effect on the tree. The date palm is affected by rain in early and late stages of pollination and in fruit ripening (Leading, 1928). The rainfall will not effect on fruit set percent few hours after pollination, because the pollen grain will directly germinate when arrive to stigma (AL-Bakr, 1972).

Pereau-leroy, (1957), sprayed water on the pollinated spadix after 4, 6, 16, 24 hour from pollination, and he found that the rain or water spray occurs after 4 hours or after 6 hours from pollination, reduced the fruit set to one third or one fourth. Ream and Furr, (1970), found that when the water was sprayed on spadix 30-60 minutes after pollination, the fruit set percentage was reduced to $30-50 \%$.

In another experiment by spraying water or rain falling 4 hours after pollination, the fruit set percent was dropped to 25\%. (Ream and Furr, 1969). EL-Kassas, et al (1996), found that the fresh male strands (have high moisture content) slightly reduced bunch weight in Zaghloly cultivar, but improved the fresh weight per fruit and physical or chemical fruit properties.

Nixon and Carpenter, (1978), found that the high R.H may cause more damage to flowers than the heavy rain followed by clear and dry wind.

Zaid and De wet, (2002), found that the effect of rain on date palm trees could be summarized in three reasons.

1. Rain fall considered as a washing agent; that take away most of the applied pollen. 2. Low temperature that follows the rain, it will reduce the flower receptivity when it contact to rain. In fact, high temperatures inhibit the pollination process due to its effect on stigma receptivity, also the low temperature have negative effect on the fruit set especially in early season. There information could be in parallel Reuther and Crawford, (1946), have concluded that an average temperature of about $35 \mathrm{C}$ is optimum for pollen germination, and low temperature decreased the germination percentage of pollen grains. Pollen grain germination was increased by temperature 7$32 \mathrm{C}$ and there was a decline when temperature rises to 43C (Furr and Ream, 1971).

Reuveni et al, (1986), reported that the fruit set was improved from bagged inflorescence might not always be attributed to the improved temperature condition, but it probably delays drying of the style and permits the normal progress of the pollen tube into the ovule even at relatively low temperatures. Also EL-Salhy, (2000) noticed that bagging of cultivar after pollination causes highest bunch weight, compared with control. In addition, the bagging improved the physical and chemical fruit properties, especially in hot and dry weather regions. Abdalla et al, (1996), reported that, the yield and bunch weight were higher in low temperature (30-36C ) and high relative humidity region (42-66\%) than in high temperature and low relative humidity region (35-42C and $26-41 \%$ R.H. 
3. The rain fall was responsible for increasing the relative air humidity creating favorable condition for cryptogamic disease that causes rotting of inflorescences. The female flower have the ability to be pollinated for 4 days from opening of the female spathes, but if there was high humidity (45\%) and moderate temperature $\left(35 \mathrm{C}^{\circ}\right)$, the pollination can be extended to more than a week (Zaid and De Wet, 2002). This is due to the effect of humidity on the receptivity of female flower. If relative humidity is very high, the pollen grains will swell and it will shrink to the humidity dropped down.

Most of studies indicated that the receptivity gradually declined after spathe cracking, and that low percentage of fruit setting were obtained, when pollination was delayed more than 10 days, (Leading, 1928). ALbert, (1930), working on 'Mactum' date showed that, after 6 days, the percentage of fertilized dates decreased quite rapidly until the thirteen days. Ream and Furr, (1969), reported that, if the pollination is delayed after spathe cracking for seven days, the fruit setting percentage will not decrease. Rahim, (1975), also showed that the high fruit set, was obtained when pollination was performed within 5 days after flower bunch appearance.

Nasr, et al, (1988), found that, the delaying pollination for 6-8 days after spathe cracking was usually safe, and that probably satisfactory fruit setting might be obtained for 10 days after spathe cracking but if the pollination delaying for more than 10 days, the fruit setting is greatly reduced. According to Djerbi (1980), the receptivity period for North African cultivars varies from one variety to another. Also Dowson, (1982), in Iraq, found that the receptivity of 'Ashrasi' variety was to be optimum before the natural opening of the male spathe. In 'Zahidi' variety, the stigma has a receptivity period for 10 days (AL-Heaty, 1975).this may be related to many factors such as relative humidity, pollen grains viability

In north and south Jordan Valley, it was observed that, if the rain fall occurs during or after short time of pollination, it causes the fruit set percentage to drop off, and then the yield will decrease too (Al-Bakr, 1972 and Al- Ekidy, 2000).

The main objective for this work is to study the effect of rain fall on pollination after different time period during anthesis by water spray treatments to determine in what time will do pollination again at the falling rain.

\section{Material and method}

\subsection{Location}

The field work of this experiment was carried out at Ghor Al Safi Agricultural Station / Ministry of Agricultural / Jordan. The laboratory work was done at Faculty of Agriculture at Mu'tah University.

\subsection{Plant material}

Two cultivars ('Hayani' and 'Zaghloly') with six date palm tree for each cultivar were selected for this study. These cultivars were planted in 1973 and in 1984, respectively. The trees for this experiment were chosen according to their uniformity in each cultivar,and they received the same cultural practices during growing season.

The pollen grains were obtained from one source and the male spathes were collected after they had been mature. Pollination was done in March, 19 and March, 22 for 'Hayani' and 'Zaghloly', respectively.

\subsection{Experimental works}

2.3.1 Pollen grain germination test

The pollen grains germination was determined according to ALbert, (1930) using media contains $15 \%$ sucrose and $1 \%$ agar. Thirty seven and half grams of sucrose was added to $2.5 \mathrm{gm}$ of agar in $250 \mathrm{ml}$ volumetric flask and boiled; the volume then was completed by distilled water with stirring the mixture. This media was poured in 12 petri dishes, then autoclaved for 2 hours at $120 \mathrm{C}$ and 1.5 bars for sterilization.

Half gram of pollen grains was sprayed on this medium; the petri dishes were placed in an incubator at $27^{\circ} \mathrm{C}$ for four days. Finally the Germination percent was calculated under light microscope at 4000X, by taking from each petri dish sections of media and calculate the total number of pollen grains and the germinated ones in these sections under microscope. Initiation of a pollen tube growth is an evidence of germination. Percent of pollen grains germination was calculated as follow:

$\%$ of germination $=$ Number of germinated pollens

Total number of pollens

$$
\text { X } \quad 100
$$

\subsubsection{Pollination methods}

Hand pollination was done by separating four strands of male flower from freshly opened male spathe and insert them, length wise and in an inverted position, between the strands of the female inflorescence spadix.

2.3.3 Water spray treatments

Six spadixs on each tree were determined for both cultivars by removing the early and late showing ones. Each treatment had two female spadixs in each tree (replicate). There were twelve spadixes for each of the following treatments for 'Zaghloly' and 'Hayani'. 
1. Without water spray (control).

2. Water spray 3 hour after pollination time.

3. Water spray 6 hour after pollination time.

Each treatment was applied on two spadixs randomly and replicated 6 times (trees) for 'Zaghloly' and 'Hayani'. That means; 3 treatments were applied on every tree, each treatment was distinguished by specific label.

Treatment key

T1: Without spray.

T2: Water spray after 3 hours from pollination.

T3: Water spray after 6 hours from pollination.

\subsection{Measurements}

\subsubsection{Fruit set percent}

Ten strands were chosen randomly from each female spadix for each treatment to calculate fruit set percent. Number of fruit, on each strand was counted, and fruit set was calculated in two different stages during fruit growth. The first count, was done 6 weeks after pollination (Hababuk stage), the second count, was done 10 weeks after pollination (Kimri stage). Fruit set percentage was calculated by the following equation:

$\%$ of fruit set $=\quad$ Number of seted fruits

Total number of flowers

X 100

\subsubsection{Yield}

Fruit were harvested on August, 10 and August, 14, for 'Hayani' and 'Zaghloly' respectively and the yield was recorded in $\mathrm{Kg}$.

2.4.3 Physical and chemical measurements of fruit:

2.4.3.1 Physical properties

Samples of 10 fruits were randomly selected from each replicate for each treatment, to calculate the weight of fruit, seed weight, flesh weights $(\mathrm{g})$, ratio between flesh and seed weight, length and diameter $(\mathrm{cm})$ by using caliper, and the ratio between length and diameter( L/D), then the means of these characters were calculated.

2.4.3.2 Chemical properties

2.4.3.2.1 Estimation of moisture percentage

The moisture percent was estimated by cutting five fruits from each replication for each treatment after seed was isolated, then samples of $5 \mathrm{~g}$ from these fruits were taken, after that, they were put in vacuum oven at 65 $70 \mathrm{C}$ until constant weight. Finally the percent of moisture was calculated by the following equation:

Moisture percentage $=\quad$ Fresh weight - Dry weight

2.4.3.2.2 Total soluble solids

$$
\text { Fresh weight }
$$$$
\text { X } 100
$$

Four fruits from each replication were chopped into small pieces and then crashed, place in cloth and squeezed. For juice extracting, Abbe refractometer was used for TSS.

2.4.3.2.3 Total soluble sugar determination:

Anthron method, used to estimate the total soluble sugar bath.

The absorbance was read in spectrophotometer at $620 \mathrm{~nm}$. (Experiments in plant physiology, 1998).

2.4.3.2.4 Reducing sugar determination

Luff Schorl method, used to estimate the reducing sugar in date fruits. Scope of this procedure is to determine the carbohydrate or reducing sugar in date fruit.

Randomized Complete Block Design (RCBD) was used with 3 treatments, with 6 replications for 'Hayani' and 'Zaghloly'. Data were statistically analyzed using Duncan's Multiple Range Test (DMRT) for comparison of means, under $0.05 \%$ probability level.

\section{Result and discussion}

3.1 Pollen grain germination test

The pollen grains were cultured in media contains sucrose and agar on April, 13. After 4 days (April, 17), the germination percent was calculated for 12 samples and the mean of these samples was $72.8 \%$.

\subsection{Fruit set percent}

\subsubsection{Hababuk stage}

Results showed that the highest fruit set percentage (47.02\%) in 'Hayani' at Hababuk stage, was obtained by control (without water spray) while the lowest percentage $(27.89 \%)$ was obtained from water spray after 3 hours from pollination table (1). With regard to 'Zaghloly', the highest fruit set percentage $40.48 \%$ was resulted from control (without water spray), and lowest $26.68 \%$, resulted from with water spray 3 hours after pollination, as 
shown in table (2).

3.2.2 Kimri stage

Results showed that there were significant differences among the treatments related to fruit set percent in Kimri stage for 'Hayani' and 'Zaghloly' dates, table (1) and (2). The highest fruit set percentage 32.53\% and $29.24 \%$ were obtained by control (without water spray) for 'Hayani' and 'Zaghloly' dates, respectively. But the lowest fruit set percentage was obtained by water spray after 3 hours from pollination for the two cultivars; it was $18.01 \%$ and $15.05 \%$ for 'Hayani' and 'Zaghloly' dates, respectively.

Analysis of variances for fruit set percent Table showed significant differences among the different treatments. As indicated in tables (1) and (2), water spray after 6 hours from pollination gave higher percent than 3 hours for both cultivars. In other word, the time of water spray has negative effect on fruit set percent, especially after 3 hours from pollination which decreased the fruit set to approximately $50 \%$ in contrast with control treatment, and that is possible due to the affect of water spray by: leaching of pollen grains, or dilution of stigmatic liquid that cause decreasing in pollen grain germination or by increasing the relative air humidity, that cause swelling of pollen grains. While the fruit set percentage was decreased to $20-30 \%$ when water sprays 6 hours after pollination, when it was compared with control treatment. In other words, pollen grain needs times between 6-8 hours to germinate. Reuveni et al, 1986, reported that the most of pollen tubes reach the base of the style of 'Hayani' date within 6 hours.

\subsection{Yield per bunch}

Results of yield indicated that there were significant differences among different pollination treatments as shown in tables (1 and 2). The highest yield per bunch $(10.46 \mathrm{~kg}$ and $11.38 \mathrm{~kg})$ for 'Hayani' and 'Zaghloly', respectively, which was obtained from control (without water spray), while the water spray after 3 hours from pollination gave the lowest yield $(5.98 \mathrm{Kg}, 8.32 \mathrm{~kg})$ for 'Hayani' and 'Zaghloly', respectively. Timing of water spray has a negative effect on yield, when water spray after 3 hours from pollination, the yield was decreased to $(50 \%$ and $30 \%$ ) for 'Hayani' and 'Zaghloly', respectively, but after 6 hours from pollination, the yield decreased to $20 \%$ in 'Hayani' date and $10 \%$ in 'Zaghloly' date. These results could be possible due to the negative affect of water spray on fruit set, either by pollen grain leaching or decreasing the pollen grains viability or affecting on stigmatic liquid.

\subsection{Physical properties}

\subsubsection{Average fruit length}

Results in tables (1 and 2$)$ indicated that, time of water spray did not affect fruit length in both cultivars. The highest fruit length was obtained with water spray after 3 hours from pollination treatment and lowest one was from control treatment (without water spray) in 'Hayani' and 'Zaghloly' dates.

3.4.2 Average fruit diameter

Fruit diameter was significantly affected by time of water spray in 'Hayani' date as shown in Table (1). The highest fruit diameter $(2.46 \mathrm{~cm})$ was obtained from water spray 3 hours after pollination and the lowest $(2.17 \mathrm{~cm})$ obtained from control (without water spray). Time of water application has significantly affected fruit diameter in 'Hayani' date, especially, 3 hours after pollination, where this treatment gave highest fruit diameter which could be due to the increasing in fruit weight, that positively affect fruit diameter in 'Hayani' date. The statistical analysis showed that there were no significant differences in fruit diameter of 'Zaghloly' date among the treatments as shown in table (2). Water spray 3 hours after pollination gave higher fruit diameter compared with control (without water spray) and water spray 6 hours after pollination.

Water spray after 3 hour from pollination has a positive effect on fruit diameter in 'Hayani' and 'Zaghloly' cultivars, but this effect was not significantly to 'Zaghloly' cultivar.

\subsubsection{Length/Diameter Ratio}

The data in table (1) illustrated that there were significant differences among the treatments in relation to length/diameter ratio in 'Hayani' date. The highest ratio was obtained from control treatment (2.35), and the lowest (2.16) was from water spray after 3 hours from pollination. However, the pollination without water spray treatment has significant differences in comparison with other treatments and these results maybe due to the small fruit diameter in 'Hayani' date. But there are no significant differences between water spray after 3 hours and water spray after 6 hours. Generally, water spray after 3 hours from pollination gave lowest fruit length/ diameter ratio in 'Hayani' date. In 'Zaghloly' date (Table 2) there were no significant differences among the treatments. The indication of this result may be due to the cultivar, which not significantly affected on fruit length or diameter by water timing spray.

3.4.4 Average fruit weight

It was noticed in tables (1 and 2) that, the fruit weight was significantly affected by time of spray in both cultivars. Fruit weight had negative influence on the yield, whereas, the fruit weight will decrease if the yield and fruit set percent will increase. 
The highest mean fruit weight $(22.06 \mathrm{~g})$ and $(25.38 \mathrm{~g})$ were obtained from water spray after 3 hours from pollination treatment for 'Hayani' and 'Zaghloly' respectively. The lowest mean weight (18.73 g) and (20.92 g) were obtained from control treatment (without water spray) for 'Hayani' and 'Zaghloly' ,respectively, which could be related to the competition between the fruits for water and nutrient.

Also the time of water spray, especially, after 3 hours from pollination, has positive effect on fruit weight, where the highest fruit weight has occurred in it, in two cultivars. The present study indicates that fruit weight was negatively related to yield and fruit set, where the more fruit set percent and yield are, the less fruit weight is, as a result of competition increase among fruit in order to get food as shown in table (1) and (2) in the two cultivar.

3.4.5 Average flesh weight

Flesh weight in both cultivars was not significantly affected by all treatment applied tables (1 and 2). However gave higher flesh weight was for 'Zaghloly'. In general, higher flesh weight was obtained from water spray after 3 hours from pollination, and lowest weight was in without water spray treatments. This was possible due to the highest fruit weight in this treatment that cause highest flesh weight.

3.4.6 Average seed weight

Seed weight in both cultivars was not significantly affected by all treatment applied tables (1 and 2), but the highest seed weight was obtained from water spray after 3 hours from pollination treatment in two cultivars, and lowest one was from control (without water spray).

3.4.7 Flesh/Seed Ratio

Flesh/ seed ratio in both cultivars was not significantly affected by all treatment applied tables (1 and 2), The highest ratio was from water spray after 3 hours from pollination and water spray after 6 hours from pollination in 'Hayani' and 'Zaghloly' dates, respectively.

\subsection{Chemical properties}

3.5.1 Moisture percent (Fresh weight)

Tables ( 1 and 2$)$ showed that there were no significant differences among the treatments of the fruits for the two cultivars in related to moisture percent. The highest percent of water was resulted from water spray after 6 hours from pollination treatment and lowest one was obtained from control treatment for two cultivars.

3.5.2 Total Soluble Solid (TSS)

Tables (1 and 2) showed that the time of water spray had a significant effected on TSS of both cultivars. There was no significant difference between control treatment, and water spray after 3 and 6 hours from pollination in 'Hayani' date, but there are significant differences between water spray after 3 and 6 hours from. That means the water spray after 6 hours have bigger effect on the TSS than the water spray after 3 hours. For 'Zaghloly' date, the highest TSS percent was resulted from water spray after 6 hours followed by water spray after 3 hours.

3.5.3 Total and reducing sugars:

In tables (1 and 2), it was noticed that the time of water spray did not show any significant effect on total and reducing sugar for the two cultivars.

Table (1) Means for Physical and chemical properties in 'Hayani' date

\begin{tabular}{|l|l|l|l|}
\hline & $\mathrm{T} 1$ & $\mathrm{~T} 2$ & $\mathrm{~T} 3$ \\
\hline Fruit set \% at Hababuk stage & $47.02 a$ & $27.89 c$ & $38.88 \mathrm{~b}$ \\
\hline Fruit set \% at Kimri stage & $32.53 a$ & $18.01 c$ & $28.47 \mathrm{~b}$ \\
\hline Yield (Kg) & $10.46 a$ & $5.98 c$ & $7.92 \mathrm{~b}$ \\
\hline Fruit length (Cm) & 5.10 & 5.32 & 5.22 \\
\hline Fruit diameter (Cm) & $2.17 b$ & $2.46 a$ & $2.42 a$ \\
\hline Length/diameter & $2.35 a$ & $2.16 b$ & $2.16 \mathrm{~b}$ \\
\hline Fruit weight (gm) & $18.73 c$ & $22.06 a$ & $19.38 \mathrm{~b}$ \\
\hline Flesh weight (gm) & 16.98 & 20.2 & 17.71 \\
\hline Seed weight (gm) & 1.51 & 1.73 & 1.61 \\
\hline Flesh/seed & 11.25 & 11.68 & 11.00 \\
\hline Moisture \% & 24.91 & 26.56 & 34.08 \\
\hline TSS \% & $50 a b$ & $49.60 b$ & $52.80 a$ \\
\hline Total sugar \% & 0.51 & 0.76 & 0.77 \\
\hline Reducing sugar \% & 0.23 & 0.33 & 0.34 \\
\hline
\end{tabular}

* Values within same rows that have different letters are significantly different at 0.05 level of probability according to DMRT. 
Table (2) Means for Physical and chemical properties in 'Zaghloly' date

\begin{tabular}{|l|l|l|l|}
\hline & $\mathrm{T} 1$ & $\mathrm{~T} 2$ & $\mathrm{~T} 3$ \\
\hline Fruit set \% at Hababuk stage & $40.48 a$ & $26.68 c$ & $32.36 \mathrm{~b}$ \\
\hline Fruit set \% at Kimri stage & $29.24 a$ & $15.05 c$ & $21.58 \mathrm{~b}$ \\
\hline Yield (Kg) & $11.38 a$ & $8.32 c$ & $10.28 \mathrm{~b}$ \\
\hline Fruit length (Cm) & 5.46 & 5.63 & 5.50 \\
\hline Fruit diameter (Cm) & 2.82 & 2.95 & 2.87 \\
\hline Length/diameter & 1.94 & 1.91 & 1.92 \\
\hline Fruit weight (gm) & $20.92 c$ & $25.38 a$ & $23.40 \mathrm{~b}$ \\
\hline Flesh weight (gm) & 19.35 & 23.31 & 22 \\
\hline Seed weight (gm) & 1.54 & 1.69 & 1.36 \\
\hline Flesh/seed & 12.56 & 13.79 & 16.18 \\
\hline Moisture \% & 48.42 & 54.26 & 55.12 \\
\hline TSS \% & $23.92 c$ & $37.00 b$ & $43.00 a$ \\
\hline Total sugar \% & 0.61 & 0.91 & 0.92 \\
\hline Reducing sugar \% & 0.27 & 0.41 & 0.41 \\
\hline
\end{tabular}

* Values within same rows that have different letters are significantly different at 0.05 level of probability according to DMRT.

\section{Conclusion:}

The study aims at identifying the effect of water timing spray on the fruit set and yield of date palm.

Water timing spray have significantly affected fruit set, yield and fruit weight in both cultivars. Spraying water after 3 hours from pollination has resulted in the least percent of fruit set and yield. Also there is a significant effect of water timing spray on the fruit diameter, length / diameter and TSS with 'Hayani' date. There is no significant effect of water timing spray on the fruit length, flesh weight, seed weight, flesh/ seed, moisture percentage and total and reducing sugar in the two cultivars. There is a significant effect of water timing spray on the TSS with 'Zaghloly' date and on fruit diameter and length/ diameter in 'Hayani' date. Finally, the farmer must repeat the pollination, if the rainfall occurred before or after 6 hours from pollination.

\section{References}

Abdalla, M. Y., Sabour, A. M., El-Makhtoun, F. B. \& Ahmed, A. M. (1996). Effect of some environmental conditions on vegetative, yield and fruit properties of 'Sewy' date cultivar. Zagazig Journal of Agricultural research. 23(1), 137-148.

AL-Bakr, A. (1972). The date palm pollination and thinning of the fruits. The date palm. AI-Ani Press, Baghdad, Iraq. 340-389.

ALbert, D.W.(1930). Viability of pollen and receptivity of pistillate flowers. Date growers Inst .rept.9: 5-6.

AL-Heaty, A.R. (1975). Studies on pollination of date palm trees in Iraq. Third International Palm and Date Conference, Baghdad, Iraq.

Djerbi, M .(1980). Report on duty travel to Tunis, Baghdad and Pakistan. FAO Regional Project for Palm and Dates Research Centre in the Near East and North Africa, Baghdad, Iraq :10-19

Dowson, V.H.W. (1982). Date production and protection with special reference to North Africa and the Near East. FAO Technical Bulletin. 35: $294-301$.

EL-Kassas ,S. E., El-sahly, A. M. \& Abdalla, A. Y. (1996). Efficiency of pollination of 'Zaghloly' and 'Samany' date palms with male strands at certain degrees of drying. Assiut Journal of Agricultural Sciences .27(2):3745.

EL-Salhy, A.M. (2000). Effect of bagging the spathes on Zaghloly date productive under Assiut condition .Assiut Journal of Agricultural Sciences .31(3):123-134.

Estimation of total Carbohydrates in plant tissue. (1998). Measurement of total soluble sugar. Experiments in plant physiology: 148-151.

Furr, J. T. \& Ream, C. L. (1971). The influence of temperature on germination of date pollen. Punjab fruit Journal. Jan.-Dec. :114-119.

Hussein, F. (1987). Technical practice operation on date palms with special attention to methods and mechanization of date pollination. Faculty of Agriculture. Zagazig University.

Khalifa, T., Jwanh, M.Z., \& Alsalem, M. I., (1983). Palms and dates in Kingdom Saudi Arabi, Kingdom Saudi Arabia.

Leading, A.R., (1928). Determination of length of time during which the flowers of the date palm remain receptive to fertilization. Journal of Agricultural Research.36 (2):192-134.

Nasr ,T.A., Bacha, M.A. \& Shaheen, M.A. (1988). Receptivity of Pistillate flower in some Date Palm Cultivars 
in Riyadh Region .J. coll. Agric. King Saud Univ.10 (1):121-128.

Nixon, R.W. \& J.B.Carpenter.(1978). Growing dates in the united states. Agricultural Information. (207):22-35.

Pereau-Leroy, P. (1957) . Pollination in date palm. Fruits.12 (3):101-105.

Rahim, A.L. (1975). The pollination interval of Dates. Third International Palm and Dates Conference. Baghdad 30Nov. - 4 Dec.1975: 9-11.

Ream, C.L. \& Furr, J.R. (1969). The period of receptivity of flower and other factors affecting set of Date fruit. Date Grower Inst. Rept. (46):28-32.

Ream, C.L. \& Furr, J.R. 1970. Fruit set of dates as affected by pollen viability and dust or water on stigma .Ann. Date Growers Inst. Rept., (47):11-19.

Reducing sugar content, Luff Schorl method ,Food analysis.:144-163.

Reuther, W. \& Crawford, C.L. (1946). The effect of temperature and bagging on fruit set of dates. Date Growers Inst. Report 23: 3- 7.

Reuveni, O., Abu, S. \& Golobovitz, S. (1986). Date palm Pollen germination and tube elongation on pistillate flowers cultured at different temperatures. Acta horticultural. 175: 91 - 95.

Zaid, A. \& De wet, P.F. (2002). Climatic requirements of date palm .Date Production Support Program .United Arab Emirates. 